\title{
Post mortem contrast-enhanced computed tomography in a case of sudden death from acute pulmonary thromboembolism
}

\author{
KIYOSHI KIKUCHI ${ }^{1,4}$, KO-ICHI KAWAHARA ${ }^{4}$, CHIYOKO TSUII $^{2}$, YUTAKA TAJIMA ${ }^{1}$, TERUKAZU KURAMOTO ${ }^{1}$, \\ MIWAKO SHIHARA $^{3}$, YUKARI KOGA ${ }^{8}$, NAOTO SHIOMI ${ }^{11}$, HISAAKI UCHIKADO ${ }^{9}$, YOKO MORIMOTO ${ }^{5}$, \\ NAOKI MIURA $^{7}$, KENTARO MERA ${ }^{6}$, YOSHIKO OHNO ${ }^{4}$, NAOHISA MIYAGI ${ }^{12}$, TERUTO HASHIGUCHI ${ }^{4}$, \\ IKURO MARUYAMA $^{4}$, NAOHUMI HAYABUCHI ${ }^{10}$, KENJI NAKAYAMA $^{1}$ and MINORU SHIGEMORI ${ }^{9}$ \\ Departments of ${ }^{1}$ Neurosurgery, ${ }^{2}$ Radiology, and ${ }^{3}$ Cardiovascular, Omuta City General Hospital, Omuta 836-8567; \\ ${ }^{4}$ Department of Advanced Therapeutics, Field of Cardiovascular and Respiratory Disorders, Division of Laboratory and \\ Vascular Medicine, and Departments of ${ }^{5}$ Restorative Dentistry and Endodontology, and ${ }^{6}$ Dermatology, Kagoshima University \\ Graduate School of Medical and Dental Sciences, Kagoshima 890-8520; ${ }^{7}$ Veterinary Teaching Hospital and Laboratory of \\ Veterinary Diagnostic Imaging, Faculty of Agriculture, Kagoshima University, Kagoshima 890-0065; \\ Departments of ${ }^{8}$ Anesthesia, ${ }^{9}$ Neurosurgery, and ${ }^{10}$ Radiology, Kurume University School of Medicine, \\ Kurume 830-0011; ${ }^{11}$ Department of Emergency, Saiseikai Shiga Hospital, Rittou 520-3046; \\ ${ }^{12}$ Department of Neurosurgery, Yame Public General Hospital, Yame 834-0034, Japan
}

Received December 30, 2009; Accepted March 22, 2010

DOI: 10.3892/etm_00000079

\begin{abstract}
A 77-year-old woman suffered a cardiopulmonary arrest the day after transvenous embolization of dural ateriovenous fistulae. The patient died despite receiving prompt cardiopulmonary resuscitation. Post mortem computed tomography (CT) was performed to determine the cause of death. No lesion was detected on a whole-body plain CT. However, a post mortem contrast-enhanced CT (CECT) performed after the administration of intravenous contrast and cardiac compressions detected pulmonary thromboembolism. Thus, post mortem CECT was useful in determining the cause of sudden death in this case.
\end{abstract}

\section{Introduction}

Virtual autopsies based on computed tomography (CT) and magnetic resonance imaging (MRI) are now used in addition to the traditional 'body-opening' autopsies to determine the cause of death in humans (1-5).

Correspondence to: Dr Ko-ichi Kawahara, Department of Advanced Therapeutics, Field of Cardiovascular and Respiratory Disorders, Division of Laboratory and Vascular Medicine, Kagoshima University Graduate School of Medical and Dental Sciences, 8-35-1 Sakuragaoka, Kagoshima 890-8520, Japan E-mail: telo@m3.kufm.kagoshima-u.ac.jp

Key words: post mortem contrast-enhanced computed tomography, cardiac compression, pulmonary thromboembolism, forensic radiology
Pulmonary thromboembolism (PTE) is a cause of sudden death that is often difficult to diagnose with conventional imaging. Contrast-enhanced CT (CECT) is often used to diagnose PTE in living patients $(6,7)$, but no studies have established a role for post mortem CECT.

Here, we describe a case of PTE diagnosed by post mortem CECT in a patient who died as a result of post-operative cardiopulmonary arrest.

\section{Case report}

A 77-year-old woman suffering from dural arteriovenous fistulae was treated by transfemoral transvenous embolization. She had a cardiopulmonary arrest after getting out of bed on the first post-operative day. Despite receiving prompt cardiopulmonary resuscitation, the patient died.

Post mortem echocardiography showed mild enlargements of her right atrium and right ventricle, but no intracardiac thrombus. We obtained permission from the patient's family for a post mortem CT to determine the cause of death. We did not identify any specific lesion on a plain, whole-body, 64-multidetector row CT scan (Aquilion 64; Toshiba Medical Systems, Tokyo, Japan) (Fig. 1A and B). We then performed cardiac compressions at a rate of $70 / \mathrm{min}$ for $4 \mathrm{~min}$ while administering $100 \mathrm{ml}$ of nonionic contrast material (iopamidol $370 \mathrm{mg} \mathrm{I} / \mathrm{ml}$, Iopamiron 370; Bayer Yakuhin, Osaka, Japan) via a peripheral vessel at $0.5 \mathrm{ml} / \mathrm{sec}$. A subsequent post mortem CECT of the thorax showed filling defects characteristic of a large pulmonary thrombus in the left lower pulmonary artery (Figs. 1C, D and 2). Her D-dimer was also elevated at $149.2 \mu \mathrm{g} / \mathrm{ml}$. Therefore, we diagnosed PTE as the cause of death. 


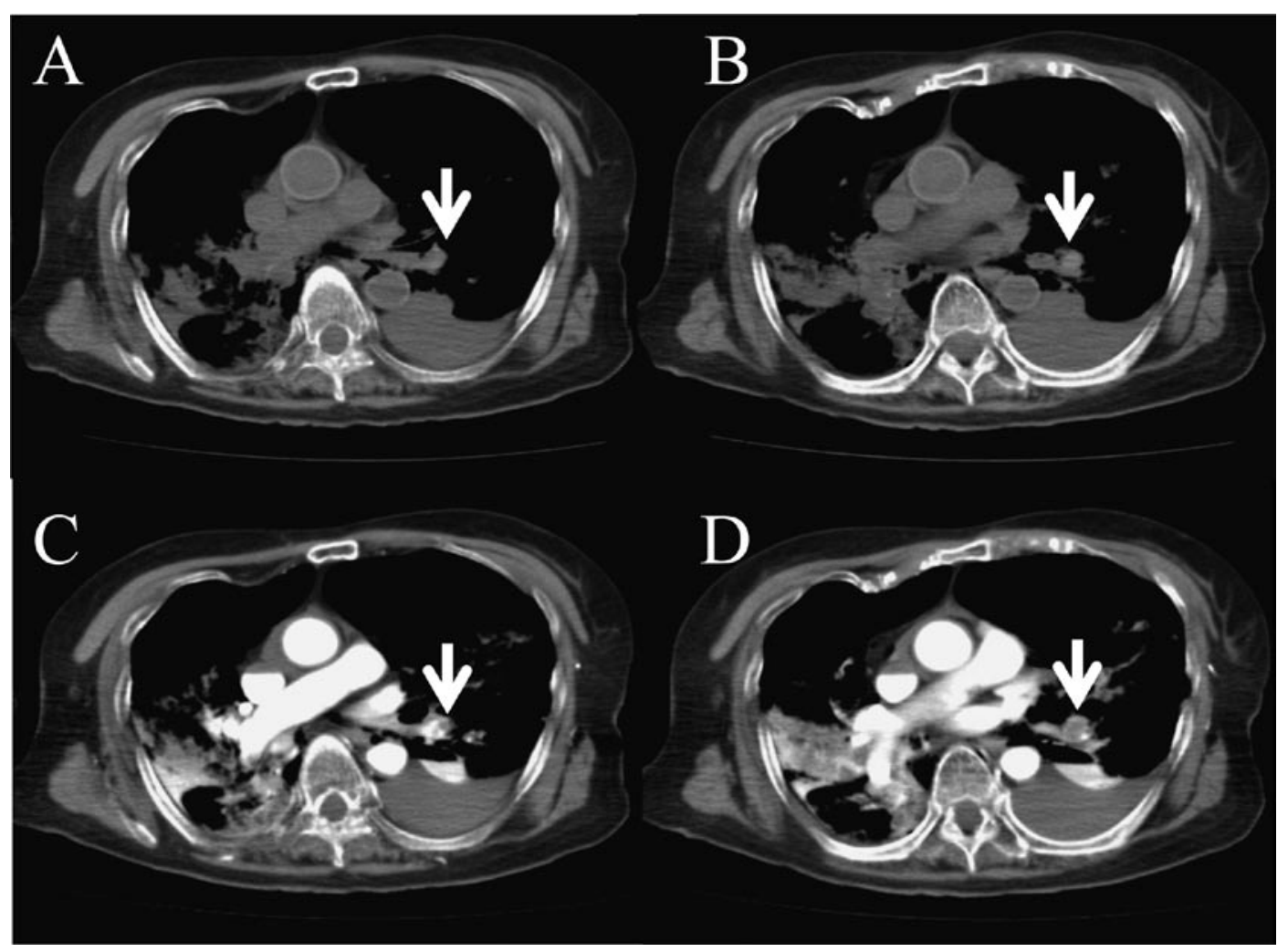

Figure 1. (A and B) Transverse plain computed tomography (CT) showing equivocal pulmonary thrombus. (C and D) Contrast-enhanced CT scan clearly demonstrating filling defects (arrow) in the left lower pulmonary artery with associated thrombus.

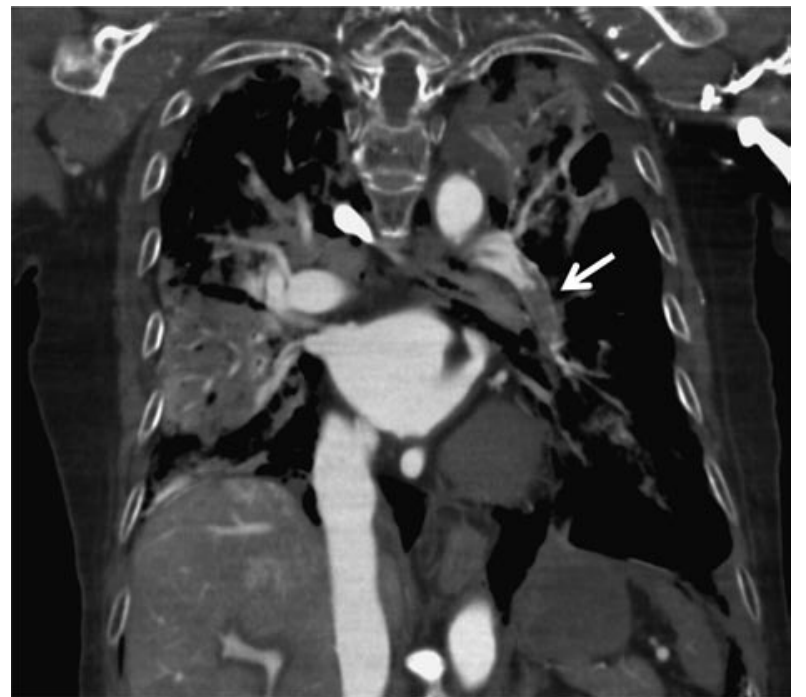

Figure 2. Coronal reformatted contrast-enhanced computed tomography image demonstrating occluding thrombus (arrow) in the left lower pulmonary artery.

\section{Discussion}

PTE is a relatively common cardiovascular emergency that is difficult to diagnose and is frequently missed (6,7). Acute occlusion of the pulmonary arterial bed may cause lifethreatening complications, and high-risk PTE has a short-term mortality rate of more than $15 \%$ (7-9). Patient-related predisposing factors for PTE include increased age, a past history of venous thromboembolism (VTE), active cancer, neurological disease with extremity paresis, medical disorders causing prolonged bed rest, such as heart and respiratory failure, congenital or acquired thrombophilia, hormone replacement therapy and oral contraceptive therapy (7). Short-term immobilization also increases the risk of VTE (6). Although these risk factors are well established, many cases of PTE still go unrecognized and untreated (6). The prevalence of PTE at autopsy is approximately $12-15 \%$ in hospitalized patients and has not changed over the last three decades (10). The rate of undiagnosed PTE in patients at post mortem has not diminished either, even in individuals who die from massive or sub-massive PTE $(6,11)$. In autopsy studies, the prevalence of unsuspected PTE, either fatal or contributing to death, ranges from 3 to $8 \%(6,10,12)$. The incidence of VTE increases exponentially with age, as do the rates of idiopathic and secondary PTE $(13,14)$. The mean age of patients with PTE is 62 years and approximately $65 \%$ are 60 years of age or older. Eight-fold higher rates of PTE are observed in patients over 80 years, compared to those younger than 50 years (15). PTE has a wide range of clinical presentations including dyspnea, chest pain, syncope, hypotension and shock $(6,7)$. First-line diagnostic tests, such as ECG, chest X-ray and blood-gas analysis, are indicated to assess the clinical probability of PTE and the general condition of the patient (6). A negative D-dimer result safely excludes the diagnosis in patients with a low or moderate clinical probability of PTE $(6,7)$. However, D-dimer has very high sensitivity but low specificity, so a positive result requires imaging to confirm the diagnosis. Specific diagnostic imaging techniques for PTE include plain chest radiography, echocardiography, ventilation-perfusion scintigraphy, CT, MRI and pulmonary angiography $(6,7)$. In 
recent years, technical advances in $\mathrm{CT}$ have prompted interest in this technique for the diagnosis of PTE $(6,7)$. However, two systematic overviews of the performance of single detector spiral CT in suspected PTE reported wide variations in sensitivity (53-100\%) and specificity (73-100\%) (7).

Invasive 'body-opening' autopsy is the traditional post mortem investigation in humans (1). Modern cross-sectional imaging techniques, however, can supplement and even partially replace traditional autopsy $(1-3,5)$. Conventional autopsies, which are often rejected by family members or certain religious groups, may eventually be replaced by noninvasive imaging (1). CT is the imaging modality of choice for two- and three-dimensional documentation and detects fractures, pathological gas collections (air embolism, subcutaneous emphysema after trauma, hyperbaric trauma and decomposition effects) and gross tissue injuries (1). The documentation and analysis of post mortem findings with CT and MRI and post-processing techniques ('virtopsy' or 'autopsy imaging') is investigator-independent, objective and noninvasive, and should lead to qualitative improvements in pathologic investigation (1,3). Potential applications for this technique include the assessment of morbidity and mortality in the general population and the routine screening of bodies prior to burial (1). A transdisciplinary research project, virtopsy, is dedicated to increase the use of modern imaging techniques in forensic medicine and pathology to augment current examination techniques and offer alternative methods (16).

In conclusion, our patient died suddenly in the hospital the day after her surgery. Although a previous study using post mortem CT reported a high success rate in detecting causes of sudden death (17), we did not find any lesion on a plain CT or CECT without cardiac compression in our patient. However, a post mortem CECT conducted after cardiac compression confirmed PTE as the cause of her sudden death.

\section{Acknowledgements}

We thank T. Fujimura and S. Sueyoshi for the excellent technical assistance.

\section{References}

1. Dirnhofer R, Jackowski C, Vock P, Potter K and Thali MJ VIRTOPSY: minimally invasive, imaging-guided virtual autopsy. Radiographics 26: 1305-1333, 2006.
2. Hayakawa M, Yamamoto S, Motani H, Yajima D, Sato Y and Iwase H: Does imaging technology overcome problems of conventional postmortem examination? A trial of computed tomography imaging for postmortem examination. Int $\mathbf{J}$ Legal Med 120: 24-26, 2006.

3. Ikeda G, Yamamoto R, Suzuki M, Ishikawa H, Kikuchi K and Shiotani S: Postmortem computed tomography and magnetic resonance imaging in a case of terminal-stage small cell lung cancer: an experience of autopsy imaging in tumor-related death. Radiat Med 25: 84-87, 2007.

4. Kikuchi K, Kawahara KI, Biswas KK, et al: HMGB1: A new marker for estimation of the post mortem interval. Exp Ther Med 1: 109-111, 2010.

5. Mitka M: CT, MRI scans offer new tools for autopsy. Jama 298: 392-393, 2007.

6. Task Force on Pulmonary Embolism, European Society of Cardiology: Guidelines on diagnosis and management of acute pulmonary embolism. Eur J Heart 21: 1301-1336, 2000.

7. Torbicki A, Perrier A, Konstantinides S, et al: Guidelines on the diagnosis and management of acute pulmonary embolism: the Task Force for the Diagnosis and Management of Acute Pulmonary Embolism of the European Society of Cardiology (ESC). Eur J Heart 29: 2276-2315, 2008.

8. Goldhaber SZ, Visani L and de Rosa M: Acute pulmonary embolism: clinical outcomes in the International Cooperative Pulmonary Embolism Registry (ICOPER). Lancet 353: 1386-1389, 1999.

9. Kasper W, Konstantinides S, Geibel A, et al: Management strategies and determinants of outcome in acute major pulmonary embolism: results of a multicenter registry. J Am Coll Cardiol 30: 1165-1171, 1997.

10. Stein PD and Henry JW: Prevalence of acute pulmonary embolism among patients in a general hospital and at autopsy. Chest 108: 978-981, 1995.

11. Mandelli V, Schmid C, Zogno C and Morpurgo M: 'False negatives' and 'false positives' in acute pulmonary embolism: a clinical-postmortem comparison. Cardiologia 42: 205-210, 1997.

12. Rubinstein I, Murray D and Hoffstein V: Fatal pulmonary emboli in hospitalized patients. An autopsy study. Arch Intern Med 148: 1425-1426, 1988

13. Nordstrom M and Lindblad B: Autopsy-verified venous thromboembolism within a defined urban population - the city of Malmo, Sweden. APMIS 106: 378-384, 1998.

14. Oger E: Incidence of venous thromboembolism: a communitybased study in Western France. EPI-GETBP Study Group. Groupe d'Etude de la Thrombose de Bretagne Occidentale. Thromb Haemost 83: 657-660, 2000.

15. Hansson PO, Welin L, Tibblin G and Eriksson H: Deep vein thrombosis and pulmonary embolism in the general population. 'The Study of Men Born in 1913'. Arch Intern Med 157: 1665-1670, 1997.

16. Bolliger SA, Thali MJ, Ross S, Buck U, Naether S and Vock P: Virtual autopsy using imaging: bridging radiologic and forensic sciences. A review of the Virtopsy and similar projects. Eur Radiol 18: 273-282, 2008.

17. Oyake Y, Aoki T, Shiotani S, et al: Postmortem computed tomography for detecting causes of sudden death in infants and children: retrospective review of cases. Radiat Med 24: 493-502, 2006. 